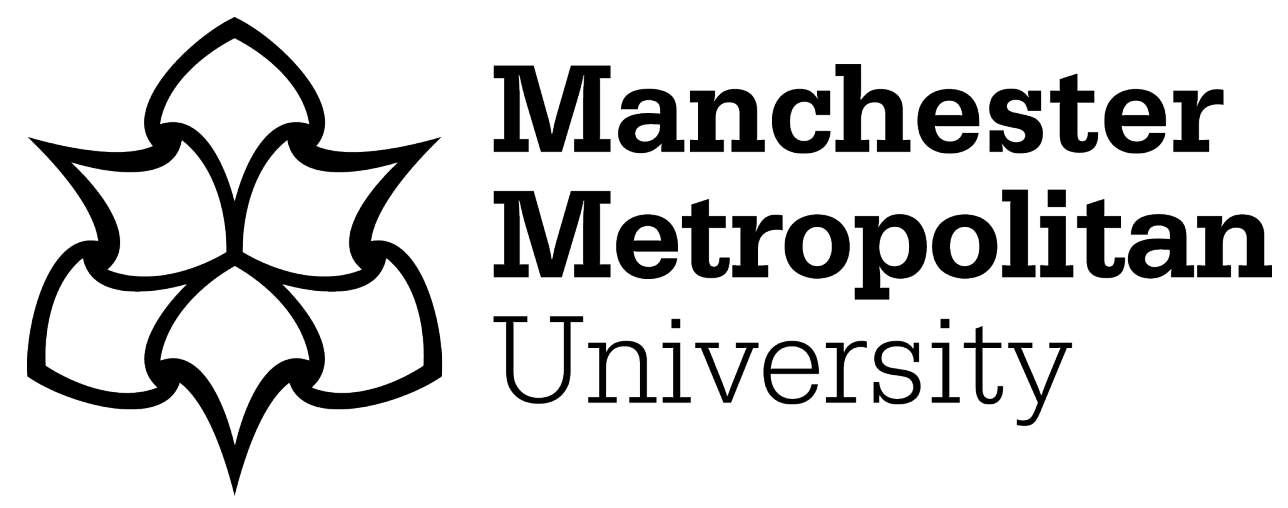

Cheetham, FC, McEachern, MG and Warnaby, GC (2018) A kaleidoscopic view of the territorialised consumption of place. Marketing Theory, 18 (4). pp. 473-492. ISSN 1470-5931

Downloaded from: https://e-space.mmu.ac.uk/618970/

Version: Accepted Version

Publisher: SAGE Publications

DOI: https://doi.org/10.1177/1470593117724608

Please cite the published version 


\title{
A Kaleidoscopic View of the Territorialised Consumption of Place
}

\author{
Short title: Territorialised Consumption of Place
}

\section{Authors :}

Fiona Cheetham, The Business School, University of Huddersfield, Queensgate, Huddersfield, HD1 3DH. Email: fiona.cheetham@hud.ac.uk

Morven G McEachern², Salford Business School, University of Salford, Salford, M5 4WT. Email: m.mceachern@salford.ac.uk

Gary Warnaby, Institute of Place Management, Manchester Metropolitan University, Faculty of Business and Law, All Saints Campus, Oxford Road, Manchester, M15 6BH. Email: g.warnaby@mmu.ac.uk

${ }^{1}$ Due to the equal input to the paper from all authors, the names are presented alphabetically.

${ }^{2}$ Corresponding author 


\section{Biographies}

Fiona Cheetham is a Senior Lecturer in Marketing in the Business School at the University of Huddersfield. Her research comprises of a number of streams, which diverge in terms of the consumer contexts studied (the socio-material practices that constitute the consumer collectables market, pet related consumption practices within the human-animal relationship and latterly the socio-material, temporal and spatial practices associated with the consumption of urban green space) but overlap in terms of her engagement with and development of ideas concerning the ontology of agency. Her work has been published in Consumption, Markets \& Culture, the Journal of Consumer Behaviour and the International Journal of Consumer Studies.

Morven G. McEachern is a Reader in Marketing at the University of Salford and Director of the Centre for Social Business. Her research interests primarily lie in the area of business and consumer ethics and various consumption contexts. In addition to international conferences, her research has appeared in Consumption, Markets and Culture, Sociology, Journal of Marketing Management and the Journal of Business Ethics. She has co-edited various Journal special issues around her research interests; contributed to edited books (e.g. The Ethical Consumer, Sage, 2005) and is co-author of Contemporary Issues in Green and Ethical Marketing (Routledge, 2014).

Gary Warnaby is Professor of Retailing and Marketing at Manchester Metropolitan University. His research interests focus on the marketing of places and retailing. Results of this research have been published in various academic journals in both the management and geography disciplines, including Environment and Planning A, Journal of Business Research, Journal of Marketing Management, Marketing Theory, Consumption Markets \& Culture, European Journal of Marketing, International Journal of Management Reviews, Area, Cities and Local Economy. He is co-author of Relationship Marketing: A Consumer Experience Approach (Sage, 2010), co-editor of Rethinking Place Branding: Comprehensive Brand Development for Cities and Regions (Springer, 2015), and has contributed to numerous edited books.

\section{Acknowledgements}

We would like to acknowledge the very helpful and constructive comments from our editor Dr Janice Denegri Knott and the anonymous reviewers on our paper. Thanks also to the organisers and participants from 'The Geography of Marketing Practices' Workshop at the University of Stockholm for their comments on an earlier draft of this paper. 


\title{
A Kaleidoscopic View of the Territorialised Consumption of Place
}

\begin{abstract}
Drawing on Brighenti's $(2010,2014)$ theoretical exposition of territorology, we extend current conceptualisations of place within the marketing literature by demonstrating that place is relationally constructed through territorialising consumption practices which continuously produce and sustain multifarious versions of place. In our fieldwork, we embrace a non-representational sensitivity and employ a multi-sensory ethnography, thus helping to illuminate the performative aspects of everyday life relating to people who use urban green spaces. Our analysis articulates three key facets relating to the process of territorialising consumption practices: (1) Tangible and intangible elements of boundarymaking; (2) Synchronicity of activities; and (3) Sensual experiences. Taken together these facets advance a kaleidoscopic perspective in which spatial, temporal and affective dimensions of the micro-practices of consumption territories-in-the-making are brought into view. Moreover, our empirical research adds an affective dimension to Brighenti's theoretical elucidation of the formation and dissolution of territories, thereby incorporating sensual imaginations and bodily experiences into the assemblages of heterogeneous materials that sustain territories.
\end{abstract}

Keywords: territory; territorialisation; non-representational theory; kaleidoscope; place; territorialising practice; green space. 


\section{Introduction}

Place can be understood as the meaningful experience of a given location; in short, place "is consumed space" (Visconti, et al., 2010: 512; Sherry 1998; Tuan 1977). Whilst place-related research has seen increased emphasis in recent years in the marketing discipline, the dominant perspectives on such research display two broad tendencies (Chatzidakis et al., 2014). The first incorporates a primary focus on place as a discrete object to be marketed to multiple stakeholders (i.e. the marketing of cities to tourists, residents and inward investors see Kavaratzis and Hatch 2013; Warnaby and Medway, 2013). The second investigates the social relations and material dimensions of place as context, for example Chatzidakis et al.'s (2012) analysis of an Athenian suburb, Hirschman, et al.'s (2012) garage, Maclaran and Brown's (2005) festival shopping centre and Visconti et al.'s (2010) urban street art. Nonetheless, a key theme throughout all this literature is a conceptualisation of place defined by Henderson (2009, p. 539) as "usually distinguished by the cultural or subjective meanings through which it is constructed and differentiated". Thus, place is rendered meaningful through the representational accounts of consumers, "framed as self-reflexive, sovereign agents who are able to recall and recount their engagement in consumption experiences" (Hill, et al., 2014) most often through the in-depth phenomenological interview. These representational accounts of place emphasise its complex, dynamic and contested character, leading Warnaby and Medway (2013) to suggest that rather than trying to reduce a given place to one dominant narrative, marketers would do better to "celebrate the complex, kaleidoscopic nature of a place" (2013: 356). Commonly interpreted as a constantly changing pattern or sequence of elements, we see potential in this use of kaleidoscope as a metaphor to apprehend various facets of place beyond purely representational narrative dimensions.

In attempting this, and to help capture the inherent complexities relating to this context (e.g. Kärrholm, 2005, 2007; Warnaby and Medway, 2013), we take a territoriological 
perspective. In so doing, we draw primarily on the influential conceptual work of Brighenti $(2010,2014)$ who defines territory in terms of "an act or practice" (2010: 53) and in relational and interactional terms, that territories "result from encounters and from the affects developed during those encounters" (2010: 57). This territoriological perspective has repercussions for the consumption of place (see Kärrholm, 2008, 2009, 2012 and his specific empirical context of urban retailing), in that instead of thinking of territory only in terms of a material, boundaried spatial entity, as is the tendency in the marketing literature (see Castilhos et al., 2016), it can also be considered as having performative and expressive aspects (see Brighenti, 2010) as well as temporal (Kärrholm, 2009) and mobile (Brighenti, 2014) attributes. It is this socio-material - and hence relational - construction of territories that we explore in empirical detail, through investigating a plethora of (individually and collectively performed) consumption activities, whose continually evolving, blending - and palimpsestic - nature combine with people, spaces and other materials (e.g. artefacts, nature). This, in turn, arguably creates a place that is in a constant state of becoming (Pred, 1984) through inter alia the creation of multiple overlapping territories. Moving away from representational views of territory, this study therefore aims to extend current conceptualisations of place within the marketing literature through interrogating the kaleidoscopic nature of territorialising consumption practices. In addition, the research provides empirical 'grounding' to Brighenti's $(2010,2014)$ theoretical exposition and, in so doing, develops it further.

Influenced by ideas developed in other disciplines, researchers are increasingly turning to relational ontological frameworks to inform the development of marketing theory (Canniford, 2016; Hill, et al., 2014). This is particularly evident in research focusing on the assemblage of markets and market practices (see Araujo et al., 2008; Canniford and Badje, 2016), but less evident in marketing studies focusing specifically on space and place (see for 
example Casthilos et al., 2016; Chelekis and Figueiredo, 2015). Thus, it is beneficial to consider Hill et al.'s (2014) work to evaluate what these frameworks might bring to the conceptualisation of place. As Hill et al. succinctly state, "relational ontologies can be understood as a set of approaches that understand 'things in the world' as taking on form and meaning through their relations with other things, rather than possessing any essential substance" (2014: 377). This anti-essentialist conception of things in the world is frequently captured in the use of concepts such as heterogeneous assemblage and assemblage of heterogeneous materials (see Latour, 2005 for a detailed exposition). Studies adopting relational ontological perspectives shed light on the processes by which things are enacted and performed, and in so doing highlight the instability of things that might otherwise be taken for granted, in the sense that heterogeneous assemblages are prone to disassemble (Callon, 1986; Cheetham, 2012).

We suggest that relational ontological frameworks offer a fresh perspective to the analysis of place by problematising its ontological status as a 'consumption object' (Cheetham, 2012; Chelekis and Figueiredo, 2015). Thus, we would argue that place is considerably more dynamic, multifaceted and fluid; hence 'kaleidoscopic', than (1) a contextual setting within which consumption takes place and (2) a given space to be marketed as a consumption object (i.e. a particular urban park, city square or high street) to various target markets (e.g. shoppers, tourists etc.) as traditionally referred to in the field of marketing. In contrast, we shall argue and demonstrate empirically that place is relationally constructed through territorialising consumption practices which continuously produce and sustain multifarious versions of place. In order to achieve this, we draw on Brighenti's (2010, 2014) exposition of 'territorology', together with Hill et al.'s suggestion of "growing one's own ontology" (2014: 383; see also Bajde, 2013) thereby articulating and developing this kaleidoscopic view of place. Consistent with the metaphor of kaleidoscope, territory 
formation can be regarded as an active and dynamic process in which boundaries are constantly formed and re-formed. Brighenti's anti-essentialist, and hence processual, approach emphasises the "irreducible plurality of each territory" (2010:53) and the boundary-creating assemblages sustaining them.

In the context of the consumption of urban green spaces, we suggest that an enhanced understanding of territorialisation practices may arise by bringing a non-representational sensitivity into our analysis in order to capture the "onflow of the everyday" (Canniford, 2012; Hill et al., 2014: 384; see also Henshaw et al., 2016) in this setting. Consequently, we adopt a methodological approach that fuses documentary film making, photography and walking interviews to record events and experiences as they unfold, thereby enabling us to demonstrate the "performative presentations, showings and manifestations of everyday life" (Thrift, 1997: 142). Incorporating this mode of theorising (see Thrift, 2008; Hill et al., 2014), into our analysis allows us to build upon existing marketing literature around space and place, which is generally based on the dominant representational view (see for example Casthilos et al., 2016; Chelekis and Figueiredo, 2015) and contribute further by advancing a kaleidoscopic perspective in which spatial, temporal and affective dimensions of the micropractices of consumption territories-in-the-making are brought into view. Whilst performative approaches have been described previously in terms of a 'place ballet' (see Cresswell, 2004), our research challenges this conception since our findings suggest the presence of multiple ballets, therefore questioning the veracity of a single choreography. We now move to consider territorialising consumption practices in this specific urban spatial context.

\section{Territorialising Consumption Practices in and of Urban Green Spaces}

As discussed earlier, the representational concept of territory is generally interpreted as emphasising notions of "power relations, control, borders and delimitations" (Casthilos et al., 
2016: 8; see also Chelekis and Figueiredo, 2015; Kärrholm, 2005; Sack, 1985). Following Deleuze and Guattari (1987), Brighenti (2010) offers an alternative conception emphasising what he terms three main "components"; namely territory: (1) is better viewed as "an act or practice" rather than as "an object or physical space" (p.53); (2) is created by an act of imagination rather than an imaginary entity; and (3) is recognised as an "expressive and functional device" (p.68).

Thus, territory is not necessarily a material thing, but a product of human and institutional relations: "[t]erritory is not an absolute concept. Rather, it is always relative to a sphere of application or a structural domain of practice" (Brighenti, 2010: 61). This highlights the importance of the boundaries delineating a territory, which "are a constitutive prerequisite of territory" (Brighenti, 2010: 60). The making of a territory is, therefore, "inherently related to the drawing of certain boundaries" (2014: 2). Throughout human history such boundary-drawing - and the means of marking the boundary is evident. For example, the noun 'march' is derived from the Old English word mearc, denoting a borderland or 'sign of a boundary', resulting in the use of the term 'marches' to denote often imprecisely defined areas along national boundaries, and also often leading to performative practices of 'marching' boundaries to highlight territorial demarcation (see Palmer et al, 2016). Thus, boundaries can, according to Brighenti (2010), be described and identified in terms of: (1) who is drawing the boundary (in that territory cannot be conceived of outside of its relationship with the agents undertaking the territory-making activity); (2) how the drawing is made (i.e. what 'technologies' - material and/or behavioural - are used to inscribe the boundary); (3) what kind of drawing is being made (linking to the notion that territory can be expressed by various means and is always 'qualified' in some way); and finally (4) why the drawing is being made (i.e. relating to its status as an expressive and functional device, 
domains of practice are 'multi-layered' and help illuminate the territorial effect 'inscribed' into the territorial constitution).

Brighenti notes that territorial boundaries "become the object of an on-going work of enactment, reinforcement, negation, interpretation and negotiation" (2010: 62), leading to the notion that the creation of territory is an active and dynamic endeavour, explicitly recognising its temporal and processual aspects. Implicit within this, is a sense that agency is distributed (Latour, 2005), and hence diffuses throughout a multitude of boundary-making activities, such as 'marching', mentioned above. Brighenti notes that such processual and evental perspectives on territory is evident in Deleuze and Guattari's (1987) notion of territorial movement, which identifies three 'movements' in the territorial process: deterritorialisation, reterritorialisation and territorialisation, which taken together define the relationship between the territory (however defined) and its surrounding space. Thus, a territory is a way of expressing a relationship with the world, which incorporates the specific expressive qualities of a space, together with the relationship between territory and external circumstances.

The specific nature of this territorialisation process will arguably vary with context, and the boundaries demarcating the territories of different users within urban space are constantly drawn and redrawn. Thus, users may continually shift their positions in this fluid relational space through movement, bound and/or drawn together by the different ways in which they use the space. As users' positions move in relational space, they simultaneously enact the deterritorialising and reterritorialising actions that form ephemeral territories of consumption and the (inclusive or exclusive) boundaries that surround them. Thus, for example, the 'boot camp' military-style exercise groups that often occur in urban green spaces may start with exercise in one area, before jogging to another area for another set of exercises as part of the planned fitness regime. Those participating, continually engage in de- 
and re-territorialising processes as they move through space. This has resonance with de Certeau's (1984) notion of movement through space as an enunciative act. However, this more abstract dimension of territorial movements may render the resulting territories difficult to apprehend, and thus, potentially challenge, for those that might be excluded from them, or who regard it as an incursion on 'their' specific territory. Such instances provide concrete examples of 'betrayal' (see Callon, 1986; Canniford and Shankar, 2013).

This description of potential territorialisation in the specific spatial context of this research leads to a consideration of territorial mobility. Drawing on Deleuze and Guattari (1987), this is explored by Brighenti (2014), who notes that most theorists of socio-spatial relations identify territories in terms of fixity, parcelisation and enclosure, which lead to notions of inside/outside. However, such a 'sedentarist' perspective, Brighenti argues, can be challenged if we accept that territories are constitutively imagined. Using the example of nomadic populations, he suggests that even people long depicted as deterritorialised, do in reality have territories and territorialities, just made in different ways, that are relative, "floating and multiple" (2014: 12), and which are "acts of coexistence" (2014; 13). Thus, territories can be fluid, and "[f]ar from being the epitome of fixity, territories are on-going, open productions" (2104: 15), and that "[p]aths, circulation, trajectories, mobilities are coessential to territories" (2014: 19). We therefore draw on Brighenti's $(2010 ; 2014)$ conceptualisation of territorology to frame our analysis of the consumption of urban green spaces from a relational ontological perspective, adding to this by also incorporating nonrepresentational facets as explained in the next section.

\section{Methodology}

The limitations associated with over-emphasising individual experience (via the individualistic approach of the typical in-depth interview) and failing to "direct adequate 
attention to the cultural complexity of social action and marketplace activity" are widely noted within marketing and consumer research (Moisander et al, 2009, p.330; see also Borgerson and Schroeder, 2002; Canniford, 2012; Henshaw et al., 2016; Holt and Thompson, 2004). Moreover, as the systems of representation through which meaning is created are not fixed, but rather open to change (see Moisander et al., 2009; Canniford, 2012), we investigate the 'place ballet' (see Cresswell, 2004) of urban green space by employing a multi-sensory ethnography (Pink, 2013), comprising film, photography, observation, in-depth and walking interviews with people who use urban green spaces (e.g. families, runners, cyclists, fitness groups, the elderly) across the Greater Manchester conurbation ${ }^{1}$. Together, we used these methods, often simultaneously, to record events and experiences as they unfolded such that we could be sensitive to "the ongoing movements of bodies, spaces and objects together" (Hill et al, 2014: 385). Our amalgamation of both permanent (e.g. film, photographs) and mobile/temporal (e.g. field observation, walking interview) methods facilitated different perspectives (e.g. aural, discursive, spatial, visual, tactile and olfactory), allowing us to capture both cognitive and pre-cognitive (affective and sensual) understandings and experiences of these interrelations.

That is to say, we chose this range of methods in order to help us "pay careful attention to the things that may evade interviewees' conscious awareness" (Hill et al., 2014: 383), thereby responding to calls from Canniford (2012), Hill et al. (2014) and Thrift (1997; 2008) to incorporate a non-representational sensitivity into our fieldwork. In addition, as Moisander et al. (2009) suggest, we also paid attention to the dynamics between ourselves and our participants, including non-verbal moments of hesitation, uncertainty and/or silence. Our multi-sensory ethnographic methodology therefore involved what Dewsbury has

\footnotetext{
${ }^{1}$ A focus on urban green spaces across Greater Manchester is justified on the basis that the North West has the second highest percentage of residents (i.e. 89\%) in urban areas, next to London (ONS, 2014).
} 
described as a 'witnessing' of the consumption of urban green space; a stance that is orientated towards being "in tune to the vitality of the world as it unfolds" (2003: 1923).

We believe that our methodological approach therefore makes an additional contribution to marketing theory by providing researchers with a practical means to incorporate both representational and non-representational knowledge and experience into research focus so as to provide a more holistic understanding of consumption phenomena. Fusing this variety of qualitative techniques not only allowed us a more "creative space of social explanation" (Dewsbury, 2003: 1908) but also enabled the advantages of each method's strengths at the same time as compensating for their associated limitations (Carpiano, 2009; Moisander et al., 2009). Each method is discussed more fully below.

\section{Film, Photographs \& Observations}

Visual methods were used to help access "the affective and sensual registers of the human body" (Hill et al, 2014: 384) and assemble the evocative facets of urban green spaces and their sensory experience. Given that walking is fundamental to understanding social life (de Certeau, 1984), our focus was on walking through such spaces, taking routes employed by different users, thereby revealing personal and subjective interpretations of urban green space. Following Belk and Kozinets (2005), the combinations of visual images and fieldnotes were important in helping to create a map of the sights, sounds, feelings, atmospheres and interactions witnessed during our walks. However, due to the constant transformation of such space (Spencer, 2011; Brighenti, 2014), it was necessary to complement our visual understandings with an aural and discursive interpretation of the meanings/experiences held by these peripatetic users.

\section{In-depth \& Walking Interviews}


Our walking interviews followed a post-structuralist approach to the personal interview (Moisander et al., 2009), in which we were cognisant of ourselves as active participants in the unfolding consumption experiences of our participants as we accompanied them on their preferred routes through urban green space (Kusenbach, 2003). In an attempt to encapsulate how "physical, social and mental dimensions of place and space interact within and across time" (Capriano, 2009: 264), fifteen interviews and twenty 'walking' conversations ${ }^{2}$ took place over a variety of days of the week, time-periods and seasons. As all participants exhibited a reluctance (some explicitly, others implicitly) to be accompanied for their whole visit, our data was sourced from partial routes around the urban green spaces in question. Interviews were audio-taped and lasted between 10-120 minutes.

\section{Abductive Analysis}

As per traditional ethnographic narratives, our analysis of the discursive, visual ${ }^{3}$ and aural is intertwined (Pink, 2013), and attends in part to the unfolding aspects of experience as we moved through space with our participants and in part to documentary observations of spacein-use. After making verbatim transcriptions of twenty-six hours of interview and thirty-eight hours of video recordings, the transcripts were read and re-read and the visual images viewed and reviewed by the researchers with our attention focusing on the minutiae of our various encounters and observations. Reflections on our visual data transported each of us back to the urban green spaces that we visited, thereby invoking memories of both our participants and our own sensual experiences of spatial arrangements, including the "spaces between individuals" (Deleuze and Guattari, 1994: 176). We employed an iterative process of "ethnographic imagination", which entailed "bringing concepts into a relationship with the

\footnotetext{
${ }^{2}$ Also referred to as the "go-along" interview method.

${ }^{3}$ Due to length restrictions, note that only a small number of visual representations are included within this paper.
} 
messiness of ordinary life, somehow recorded" (Willis, 2005: xi) so as to try and make sense of territorialisation processes. Bringing concepts primarily from the work of Brighenti (2010, 2014), but also from that of Hill et al. (2014) and Canniford and Badje (2016) into a relationship with our multi-sensory fieldwork approach allowed us to identify three key facets of the process of territorialisation, which we shall explain in the next section. In as much as it is feasible for a textual-based paper, our abductive analysis attempts to illustrate the active and dynamic nature of territorialisation: in sum, the on-going process of territorialisation and hence the becoming of place.

\section{Incorporating Non-representational Sensitivities into the Analysis of Territorialisation}

As indicated above, our abductive analysis suggests three key facets of the process of territorialisation: (1) Tangible and intangible elements of boundary-making (spatial dimensions of territorialisation); (2) Synchronicity of activities (temporal dimensions of territorialisation) and (3) Sensual experiences (affective dimensions of territorialisation). These dynamic, fluid and interrelated facets of territorialisation embrace assemblages (Canniford and Badje, 2016) and subsequent dispersals of heterogeneous materials that accrue in the process of bodies (our participants and ourselves) moving through urban green spaces at different times of the day, week and month and for varying lengths of time. Since the proposed facets are clearly interrelated, we employ the kaleidoscope as a metaphor so as to single out and shed light on each of the three facets in turn, at the same time as refracting aspects of the remaining two facets.

\section{Tangible and Intangible Elements of Boundary-Making}

Brighenti argues that boundaries "are a constitutive prerequisite of territory" (2010: 60), so it therefore makes sense to begin our analysis of the process of territorialisation by examining 
boundary-making practices. Our observation of the tangible and intangible elements of boundary-making emerged through the process of reviewing scenes that we had captured in our films and associated photography. Whilst the agency of many tangible boundaries is recognised and commented on by participants during our walking interviews, it is our identification, through extended periods of observation, of the performativity of what we might term primarily intangible boundaries that helps to shed light on boundary-making as an integral aspect of the process of territorialisation (Brighenti, 2010) in this context. This facet draws the spatial dimensions of the process of territorialisation into the foreground although, as we shall see, temporal and affective dimensions kaleidoscope in and out of view.

A fairly wide range of tangible boundaries are evident when we examine our visual materials; not least the various perimeter fences/gates that serve to enclose a number of the urban green spaces visited, thereby restricting their availability to the general public to certain opening times. Other noticeable permanent tangible boundaries are those involving various barriers either designed to protect children and/or for health and safety reasons more generally (e.g. barriers around a lake). Almost every urban green space that we visited had fences of various kinds surrounding the children's play areas (see image 1), ranging from tall, wire or metal security-type structures to low wooden fences. In our walking interviews, a number of participants commented positively about these tangible barriers. For example, on approaching a children's play area with a participant and her young children, she directed her gaze away from the path immediately in front of us, towards the play area, as she suggested: "so you can see that its fenced off here...in fact a lot of parks now fence off the play area and I think that helps to keep child areas safe from a stray football, for example" (Female, early 30's). While there are signs forbidding certain older groups from entering the children's play areas; social norms are also likely to ensure that older children/people without children do not enter these areas. Approaching a play area during another of our walking interviews, a 
participant maintained that "there's a kind of unwritten rule that everyone abides by, $y$ 'know, the dog walkers keep away from the children, the children don't bike near the dog walkers" (Male, 40s). This is something that we paid considerable attention to whilst filming near to children's play areas and not once did we see a violation (although this is not to suggest that this would never occur).

On a different occasion, after an hour of watching and filming two fishermen from 25 metres away, we observed that none of the passers-by approached the fishermen, nor did anyone approach the shoreline of the expanse of water where they were fishing. In this instance, whilst there was no tangible barrier (i.e. fence or sign), we might conceive of an 'invisible wall' surrounding and protecting the peace and quiet of these two men from any unwanted intrusions, reinforcing their personal space, or territory (see image 2). This can be explained, as Brighenti (2010) has suggested, by the fact that territories may be conceived as an act or practice. That is to say, the space inhabited by these two men becomes a quiet and peaceful spot by virtue of multiple heterogeneous materials (fishing rods, body of water, riverbank, men dressed in particular attire, tents, the lack of conversation etc.) being assembled in close proximity such that the practice of fishing is rendered clear for all to appreciate. This assemblage of heterogeneous materials (Canniford and Badje, 2016; Latour, 2005) assists onlookers to sense (Hill et al., 2014) the significance of this space (here we witness affective dimensions filtering through the kaleidoscopic scene), which then serves as an intangible boundary operating to reduce the likelihood of outsiders entering. This example provides empirical evidence in support of Brighenti's (2010) insightful theorisation of territorialisation as practice and thereby helps to illustrate the relational ontology of territorialisation: in line with Brighenti (2010) we are suggesting that the 'fishing territory' captured in image 2 has no a priori existence as such. It is "not a pre-existing container in which things are embedded" (Castilhos et al., 2016: 3). Instead, this consumption territory is 
performed into being through the (temporary) relations between the heterogeneous materials described above, which embrace spatial, temporal and affective dimensions.

Of course, there will be a variety of explanations as to why other users do not enter into the personal space inhabited by these fishermen. Some will be readily available to conscious awareness (i.e. not wanting to disturb their peace and quiet, holding the belief that there is nothing much to see). However, other explanations may be less obvious: one such explanation we term 'keeping to the path'. With regards to the notion of the path serving as a tangible territorial boundary that operates below conscious awareness, we found it fascinating to observe just how many users (ourselves included) followed the trail of paths leading through the various urban green spaces that we visited. Here we are referring to paths through open grassy areas (upon which people are clearly allowed to walk) as opposed to paths through formal gardens (where tacit knowledge, social norms, and the occasional small sign serve to inhibit people from walking on the flowerbeds). One scene within our documentary video of a dog running off the path and into the grass was particularly noticeable by virtue of the fact that this was in stark contrast to the human users of the space, all of whom kept to the path, at least for the duration of that particular shot. A short time later, we observed a young father pushing his daughter in a lightweight buggy on the path and, as if he had suddenly remembered he had to be somewhere else at that precise moment, he veered sharply off the path and onto the grassy hill and continued on the bumpy, grass for five minutes, before reaching the concrete path at the bottom. Thus, footpaths certainly appear to condition and contour not only people's walking routes, but also their running routes around many urban green spaces. However, this is not something that users generally discussed with us. That is to say, the pathways appear to be largely taken for granted: their agency only rendered apparent within our kaleidoscopic scene as a result of our observations of bodies moving through space. 
The ephemeral quality and kaleidoscopic tendency of territory becomes particularly evident through our film data. Thus, as heterogeneous materials disperse with the departure of the fishermen, we witness the de-territorialisation and subsequent re-territorialisation (Brighenti, 2010) of the riverbank into a play area soon after by children approaching the water to throw stones or watch the ducks. Tensions appear when dogs start entering the space, sniffing out the fishermen's leftover food and barking at the ducks.

The observations presented via this facet serve to challenge the traditional conception of territory as a distinct space. This issue will be picked up and developed further in our discussion of the two remaining facets.

\section{Synchronicity of Activities}

This facet highlights the temporal dimensions of the process of territorialisation, at the same time as spatial and affective dimensions shift in and out of kaleidoscopic view. Drawing on Lefebvre's (2004) concept of rhythmanalysis, Kärrholm (2009) emphasises what he terms 'synchronisation', which he takes to be a strategy of assembling, framing and co-ordinating flows and rhythms in time. Kärrholm considers this from the perspective of retail businesses coordinating activities such as opening hours to existing urban rhythms and mobilities of everyday life. In this sense, synchronisation is, arguably, a deliberate strategy on the part of specific actors. Our use of the term synchronicity differs from this, in that we envisage a multi-dimensional perspective in which it is possible, indeed probable, for consumption territories to overlap in space, through time, in a more organic, free-flowing and less instrumental way. This position is consistent with Brighenti, who argues that, "in most cases, territories are not mutually exclusive but rather stratified and superposed to each other" (2014: 7). The synchronicity of activities surfaced initially through reviewing our films and, again, was rarely discussed explicitly by participants. However, as we reviewed the 
transcripts with this facet in mind, we identified some of the ways in which participants interpret the synchronicity of activities within urban green space. Our analysis therefore recuperates glimpses of what our participants "nonetheless felt" (Hill et al., 2014: 383, original emphasis) in addition to aspects within their conscious awareness.

We observed a variety of activities taking place in the urban green spaces that we visited, which ranged from the fairly solitary to the more sociable. At the solitary end of the spectrum we consider the experiences of a lone runner with whom we started talking when he used the bench on which we were sitting to stretch out at the end of his run. Reviewing the transcript of this conversation we note with interest the way that he talked about the interactions and levels of sociability among individual runners: "the first time you see them, there's always a 'good morning' or an acknowledgement of some sort while running round the circuits and then sometimes, as you see them more regularly, you would talk to other runners about races that were coming up or where to go for injuries and that kind of thing while you were warming up or stretching at the end of your run" (Male, early 30's). While concurring with Thomas et al.'s assertion that community builds through "heterogeneous actors assembled around a shared commitment" as in the case of long-distance running (2013: 1012), we would add that it is the repetition of interactions between runners engaging in synchronised activities in space and over time that is important in establishing and stabilising this sense of community. That is to say, if this running community rests partly on social interaction it simultaneously materialises through shared 'possession', however temporary, of particular running routes (note the use of the term 'circuits' by the lone runner in spite of the absence of a formal running track). It is important to note here firstly, as Brighenti suggests, that "what counts is not space per se, but the relationships among people that are built through space and inscribed in it" (2010: 55), which thereby create the inclusive (and exclusive) boundaries temporarily sustaining that territory. Secondly, and following 
from this, is the theoretical idea expounded by Brighenti that the material (i.e. physical spaces) becomes transformed into the immaterial (i.e. relations) and vice versa. In this regard, Brighenti points out that "in traditional ontology, spaces and relations are two different sets of things", whereas "in social practices, these two dimensions do not simply interact but ceaselessly prolong into each other" (2010: 59). We will return to discuss the concept of prolongation shortly. At present, we move on to consider activities at the more 'social' end of the spectrum.

Towards this end of the spectrum is the annual Santa fun run we witnessed at one of the larger urban green spaces. When filming, we were conscious of trying to capture the event's fun and atmospheric excitement evident in people's facial expressions (e.g. smiling, pretend grimacing etc.) and behaviours (e.g. 'silly dancing') of observers and race participants, starting with the 'warm-up' exercises to disco music before the fun-run actually began and continuing through to the end of the race, which was accompanied by a brass band playing Christmas carols. In addition to the music, chattering and laughter, two aspects particularly stand out; first is the physical proximity of the multitude of bodies of all ages, and second is colour; all of the bodies taking part in the run are clad in bright red Santa outfits, with white trimming and white beards (see image 3). The red stands out against the bleakness of the cold winter's day and serves to further link the bodies together such that as the race begins, a veritable swarm of red bodies moves in tandem through space. Reviewing our film footage of this event alerted us to the parallels that can be drawn between this territory-in-the-making and the territorial appropriation processes of nomadic desert tribes discussed by Brighenti (2014). In this regard, Brighenti suggests that "once we begin to complexify the relation between territory and movement", we come to appreciate the idea that "territory is floating and multiple" (2014: 12). He therefore invites us to conceptualise territory as being "located at the point of convergence between...the experience of a here- 
and-now and the ensemble of prolongations of such here-and-now into other locales (as well as temporales)" (2014: 13). In so doing, we can now return to envisage the prolongations of individual runners into a sense of community, which subsequently prolongs into various running routes (once again we witness the shifting spatial, affective and temporal patterns of the kaleidoscopic scene).

Returning to the video-footage of the Santa fun run, the runners take a pre-ordained route which, like nomadic encampments, has a tangible (albeit temporary) material stabilisation (Kärrholm, 2008). This stabilisation occurs with the movement of bodies through space and time, and through the placement of marshals, their bodies adorned with high-visibility jackets, occupying strategic positions in space as way-markers to direct the runners appropriately. Steel fences and traffic cones are used to separate the runners from the general public. These are removed by marshals after the last runner passes by, thereby loosening the relationship between bodies and space (the kaleidoscopic patternings continue shifting in shapes). Affective dimensions also came to the fore as we mingled with the scores of observers and well-wishers lining the running route. In this regard, one of the onlookers with whom we got talking drew our attention to the variety of people here, nodding his head in different directions in indication, as he commented: "this is a fantastic event, it's for a great cause and there is a real sense of community as well and everyone including the elderly, parents and children all appear to be having a great time" (Male, 50's). This is not to say that everyone who visited that day took an interest in this event; there were plenty of other people who appeared to be carrying on with their usual routines (see image 3 for example where the dog walker disregards the Santa runners and continues his walk by traversing the start line of the race). This leads us into sensual experiences; the last of our three facets. 


\section{Sensual Experiences}

This facet draws the affective dimensions of the process of territorialisation into view; once again we glimpse the other facets of the process of territorialisation shifting in and out of view. Identification of this facet emerged through the multi-sensory affordances of our walking interview method, which facilitated appreciation of the unfolding vitality (Dewsbury, 2003) of daily life. As we shall see, these sensual experiences tended to emphasise 'nature versus culture' (Canniford and Shankar, 2013).

We deal first with nature-based sensual experiences. Here, as noted whilst walking with an elderly couple, the affective power of atmosphere to "unfold a sensual impact" (Biehl-Missal and Saren, 2012: 168) on us was palpable as the woman, in her late 60s divulged; "we love it...we can just come down here, it's lovely and quiet." At which point we all stopped to admire the landscape in front of us, suspending conversation to inhale the 'quiet'. On continuing our walk, the deafening, accompanying soundtrack of bickering ducks from the lake did not raise any remarks from the couple, therefore suggesting that this "lovely, quiet" experience referred mainly to the absence of other people. On a separate occasion we walked with another couple (both of whom were in their mid-60s), and on approaching a bird hide, the husband recalled that "we see loads of birds here and we have a book at home... and we look at that when we get home to see what we've seen". On stopping to enter the hide, the couple pointed to a green algae forming round the lake, commenting on the impact upon the wildlife, voicing their disapproval at the City Council for not taking action to remedy this. The steady spits of rain, together with the overhead battle-cries between birds skirmishing over bread being thrown by another person nearby, interrupts and permeates the atmosphere of our shared space and quickly draws our conversation to a close. As the couple attuned to the rhythms of the natural world, they became pre-occupied with watching the birds, rationalising further their tacit decision to remain at the bird hide (see 
image 4); sensing their retreat into a mutual private space, we took this as a cue to leave them alone. No more than a couple of steps later, their attempts to secure peace and tranquillity were disturbed as a group of raucous teenagers returning from their windsurfing activities came running towards us, racing to catch their bus home and we reflected upon the often "fragile and socially contested" relations facilitating the consumption of nature (Canniford and Shankar, 2013: 1059). Brighenti reminds us that "far from being the epitome of fixity, territories are on-going, open productions which imply the capturing of materials and the production of expressiveness" (2014: 15). If the bird hide in our example serves to assist in capturing material nature (i.e. encouraging birds to enter/remain in a particular spot) by hiding human presence, on this particular day we witnessed the limits of its expressive power on oblivious teenagers. Brighenti suggests that "territories consist of the work and craft (and time and energy) that are necessary to make a certain material become expressive" (2014: 14). We researchers could have adopted a working role here by attempting to quieten the teenagers as they passed by thereby extending the expressive power of this territory-in-the making; but we were not minded to do so.

In spite of the traffic noise from outside the green space being audible and the traffic being occasionally visible as we accompanied them on their walks, many participants spoke of their consumption experiences in terms of the opportunity to slow down a little and escape the urban pace of life and subsequently, about how removed they feel from their everyday urban lives when visiting these green spaces. Upon walking along a tree-lined pathway intermittently allowing views of dinghies and windsurfers on the lake (see image 5), one participant shared with us that: "you feel like you are in a green area and out in the fresh air - you would never think you are next to a motorway" (Female, 40's). Sentiments such as this echo the discursive resources that surfers employ in romanticising sublime nature (Canniford and Shankar, 2013: 1055), albeit that in the present context we are witnessing a rather more 
prosaic romanticisation of nature. These sentiments also attest to the work and craft involved in the on-going expressive production of territory (Brighenti, 2014).

We turn now to socio-culturally-based sensual experiences, giving due consideration to the small number of participants who expressed their irritation at having to share urban green spaces with others they perceived as undesirable (see Mitchell, 1995; Zukin, 2010) and/or threatening to safety (see Maas et al., 2009), such as the homeless and anti-social teenagers. In this regard, some participants had a preference for urban green spaces that are socially and spatially regulated through the presence of wardens since they have 'official control'. For example, one participant mentioned that "our local park has got a part-time warden...I think that's what keeps it in order. They are not there all the time but enough to make a difference, as with the older kids getting into a bit of mischief, the wardens are there nipping it in the bud and I think that's important in setting the tone and culture of that park" (Male, 40's). However it is interesting to contrast this with other examples in which tensions become apparent; either as a result of perceptions of the locations of urban green spaces or in terms of the more overtly negative material consequences of urban life. Regarding location, one resident of the affluent suburb of Sale stated that "if I went to a park in North Manchester, you might have the same facilities, but a very different park in terms of how it feels due to the issues going on in that community - like Platt Fields - I don't mind going during the day with other people but I wouldn't nip in there after school - I think the Sale ones are safer really" (Female, early 30s). Similarly, during the course of a walking interview with another participant, we encountered a gateway with bright purple graffiti (see image 6), which prompted this participant to mention previous experiences of visiting urban green spaces on Sunday mornings after younger, teenage users had obviously congregated there. In this regard, she commented; "you get people vandalising, drinking, litter everywhere and you don't want your kids playing somewhere where someone has smashed a bottle there 
the night before" (Female, mid 30s). Both of these incidents provide glimpses of prolongations of urban socio-culture into the curated and choreographed 'natural' landscape; each serving as an example of the "flow of territorial imaginations", which Brighenti argues "is at play and at work: territories are constitutively imagined (not imaginary) enterprises" (2014: 13). That is to say, our multi-sensory fieldwork approach bears witness to both affective (sense of foreboding) and material traces of what some people experience as undesirable, perhaps even dangerous, intrusions of urban socio-culture into peaceful, safe nature, relatively speaking. These prolongations may be seen as 'betrayals' (Callon, 1986; Canniford and Shankar, 2013), which act as tangible and intangible boundaries that serve to exclude some people (e.g. families with young children) from certain areas and/or at certain times. In these examples, we sense agency diffusing through assemblages of heterogeneous materials (empty beer cans, broken glass and other litter, graffiti, imagination and recollection of loutish behaviours) thereby working towards the stabilisation of these territories even in the absence of anti-social youths. This is suggestive of a more diffuse operation of power (see Foucault's 1991 treatise on the micro-processes of power), than the authoritative power bestowed by the local authority upon the local park warden. These empirical findings therefore echo, at the local level, the point that Brighenti makes at the national level, that "while the state operates as a centripetal force, it can never fully reach total exclusion of other spatial functions and practices (2010: 54).

\section{Discussion}

This study builds upon existing marketing literature around place (see for example Chatzidakis et al., 2012; Hirschman, et al, 2012; Maclaran and Brown, 2005; Visconti et al., 2010), by drawing on anti-essentialist ideas on the subject of territories and processes of territorialisation put forward by Brighenti $(2010,2014)$ to frame the analysis of small-scale 
consumption territories-in-the-making. We have used the metaphor of the kaleidoscope in an effort to capture the dynamics of 'process' and to move attention away from the twin ideas of space as a container in which consumption activities take place and place as a discrete object to be marketed (see for example Kavaratzis and Hatch 2013; Warnaby and Medway, 2013), towards the idea of consumption being integral to place-making through a multitude of territorialising consumption practices. Turning the viewer of our kaleidoscope, instead of colours we see the dimensions - time, space and affect - shifting in and out of view as territories form and take shape and then these territories disappear from view, reform and disappear from view once more.

Like all metaphors our metaphor of the kaleidoscope both illuminates and obscures. In terms of illumination, the kaleidoscope helps us to appreciate the dynamic and ephemeral quality of territory and the multiple refractions of territories-in-the-making. This perspective challenges the representational assumption of centripetal power and control, shedding light instead on non-representational aspects of the micro-practices of power relations governing how spaces are actually used and what places mean. Whilst previous research on place acknowledges the complex, dynamic and contested character of place, leading Warnaby and Medway (2013) to suggest the importance of highlighting multiple narratives of place, our research contributes to the marketing literature by illuminating the non-representational processes through which multiple conceptions of place are simultaneously produced and experienced. The effects of this are twofold. First, our study presents a theoretical challenge to previous marketing research on place (see for example Casthilos et al., 2016) which is aligned with Creswell's (2004) notion of 'place ballet'. Instead, we identify multiple ballets in performance through space and time, choreographed by multiple, heterogeneous materials. In this respect, we recall from our analysis, the prolongations of urban youth culture which serve as acts of betrayal to the carefully choreographed performance of the 'safe' urban green 
park space as well as the prolongations of individual runners into a sense of community, which sustains various running routes through space and time. Second, the detailed accounts that are rendered possible through our analytical and methodological approach provide a rich 'data set' out of which multiple narratives could be created for marketing purposes.

In terms of how the metaphor might obscure, it could be argued that the concept of a kaleidoscope makes us think only about the boundary-forming heterogeneous materials that we can see. For example, if we consider our observation of the de-territorialisation and subsequent re-territorialisation of a riverbank from a fishing territory into a play area. Here we saw the dispersal of the fisherman, their fishing rods and tent and the appearance of children, dogs and adults. However, we also sensed the atmosphere changing as peace and quiet gave way to the sounds of laughter, dogs barking and, had we been closer, we would also have heard adults chattering. We therefore invite our readers to imagine a multi-sensory kaleidoscope which incorporates not just images, but also sounds, smells and feelings.

This brings us to consider the relationship between our theoretical and our methodological approach, which are necessarily tied. Following Hill et al.'s (2014: 390) recommendation that non-representational sensitivities should accompany representational research "to refresh and drive our field forward in innovative ways," we employed a multisensory ethnographic approach to fieldwork in order to witness events as they unfolded. Such an approach not only facilitated access to sensory understandings that may often evade interviewees' (and indeed, interviewers') conscious awareness (such as keeping to the path), but it also permitted a deeper appreciation of the transitory qualities and inherent flux in our everyday experiences of spaces and places. Our methodological approach and analysis therefore makes two contributions to marketing theory. First it provides a practical example of how research methods can be combined in order to try and access the 'nonrepresentational' thereby pioneering a path towards exploring the affective intensities of 
space, opening up the possibility for wider applications of the theoretical discussions initiated by Canniford (2012) and Hill, et al. (2014) within our discipline.

Second, our research draws Brighenti's (2010; 2014) general science of territorology into the discipline of marketing, demonstrating its theoretical value at the same time as adding to it by giving an empirical grounding to his theoretical exposition in a specific localised context. However, in comparison to Brighenti $(2010,2014)$ who tends to focus his discussion at the macro-meso and theoretical levels of analysis, our visual and textual vignettes explore the meso-micro and empirical levels of analysis. In so doing, our research is able to add an affective dimension to Brighenti's theoretical elucidation of the formation and dissolution of territories, thereby incorporating sensual imaginations and bodily experiences into the assemblages of heterogeneous materials that sustain territories.

We conclude by inviting researchers to build on our work by taking these methodological and theoretical ideas to inform marketing analyses in other spatial contexts of consumption to develop new approaches in the domain of service environments and store atmospherics, and to challenge the concept of servicescape as an inherently managed space. In this regard, the concept of territorialising consumption practices provides researchers with a point of departure from which to challenge traditional approaches which privilege the singular vantage point of marketing practice (e.g. Bitner, 1992; Chebat and Turley, 2002; Hulten, 2015; Schmitt, 1999) and analyse consumption from the essentialist perspective of co-creation (e.g. Clarke and Schmitt, 1995; Gentile, Spiller and Noci, 2007). In so doing we believe marketing scholars will be able to develop and enrich future research around the consumption of place. 


\section{References}

Araujo, L., Kjellberg, H. and Spencer, R. (2008) Market practices and forms: Introduction to the special issue. Marketing Theory 8(1): 5-14.

Bajde, D. (2013) Consumer culture theory (re) visits actor-network theory: Flattening consumption studies. Marketing Theory 13(2): 227-242.

Belk, R.W. and Kozinets, R. V. (2005) Introduction to the resonant representations issue of Consumption, Markets and Culture. Consumption Markets \& Culture 8(3): 195-203.

Biehl-Missal, B. and Saren, M. (2012) Atmospheres of seduction: A critique of aesthetic marketing practices. Journal of Macromarketing 32(2): 168-180.

Bitner, M.J. (1992) Servicescapes: The impact of physical surroundings on customers and employees. Journal of Marketing 56(2): 57-71.

Borgerson, J.L. and Schroeder, J.E. (2002) Ethical issues of global marketing: Avoiding bad faith in visual representation. European Journal of Marketing 36(5-6): 570-594.

Brighenti, A.M. (2010) On territorology: Towards a general science of territory. Theory, Culture \& Society 27(1): 52-72.

Brighenti, A.M. (2014) Mobilizing territories, territorializing mobilities. Sociologica $8(1): 0-0$.

Callon, M. (1986). Some elements of a sociology of translation: Domestication of the scallops and the fishermen of St. Brieuc Bay. In: Law, J. (ed.), Power, Action and Belief. A New Sociology of Knowledge? pp.196-233. London: Routledge \& Kegan Paul.

Canniford, R. (2012) Poetic witness: Marketplace research through poetic transcription and poetic translation. Marketing Theory 12(4): 391-409.

Canniford, R. and Badje, D. (2016) Assembling Consumption: Researching Actors, Networks and Markets. Oxon: Routledge.

Canniford, R. and Shankar, A. (2013) Purifying practices: How consumers assemble romantic experiences of nature. Journal of Consumer Research 39(February): 10511069.

Carpiano, R.M. (2009) Come take a walk with me: The "Go-Along" interview as a novel method for studying the implications of place for health and well-being. Health \& place 15(1): 263-272.

Castilhos, R.B., Dolbec, P.Y. and Veresiu E. (2016) Introducing a spatial perspective to analyse market dynamics. Marketing Theory DOI: 1470593116657915.

Chatzidakis, A., Maclaran, P. and Bradshaw, A. (2012) Heterotopian space and the utopics of ethical and green marketplace behaviour. Journal of Marketing Management 28(3/4): 494-515.

Chatzidakis, A., McEachern, M.G. and Warnaby, G. (2014) Proposed special issue on consumption in and of space and place. Available at: http://mtq.sagepub.com/site/CFP/CFP Space_Place.pdf (Accessed 20 July 2014).

Chebat, J and Turley, L.W. (2002) Linking retail strategy, atmospheric design and shopping behaviour. Journal of Marketing Management 18(1): 125-144.

Cheetham, F (2012) An actor-network perspective on collecting and collectables. In: Dudley, S.H., Barnes, A.J., Binnie, J., Petrov, J. \& Walklate, J. (eds) Narrating Objects, Collecting Stories, pp.125-135, London: Routledge.

Chelekis, J. A. and Figueiredo, B. (2015) Regions and archipelagos of consumer culture: A reflexive approach to analytical scales and boundaries. Marketing Theory 15(3): 321345.

Clarke, I. and Schmitt, R.A. (1995) Beyond the servicescape: The experience of place. Journal of Retailing and Consumer Services 2(3): 149-162.

Cresswell, T. (2004) Place: A Short Introduction, Oxford: Blackwell Publishing. 
de Certeau, M. (1984) Practices of Everyday Life. Translated by S. Rendall, Berkeley: University of California Press.

Deleuze, G. and Guattari, F. (1987) A Thousand Plateaus. Minneapolis: University of Minnesota Press.

Deleuze G and Guattari F (1994) 'Percept, Affect, and Concept'. What is Philosophy? pp.163-200. New York: Columbia University Press.

Dewsbury, J. D. (2003) Witnessing space: 'Knowledge without contemplation'. Environment and Planning A 35(11): 1907-1932.

Foucault, M. (1991) Discipline and Punish: The Birth of the Prison. London: Peguin Books.

Gentile, C., Spiller, N. and Noci, G. (2007) How to Sustain the Customer Experience: An Overview of Experience Components that Co-create Value with the Customer. European Management Journal 25(5): 395-410.

Henderson, G. (2009) 'Place', in Gregory, D., Johnston, R., Pratt, G., Watts, M. J., and Whatmore, S. (eds) The Dictionary of Human Geography (5th Edition) Chichester: Wiley-Blackwell, pp. 539-541.

Henshaw, V., Medway, D., Warnaby, G., \& Perkins, C. (2016) Marketing the 'city of smells'. Marketing Theory 16(2): 153-170.

Hill, T., Canniford, R. and Mol, J. (2014) Non-representational marketing theory. Marketing Theory 14(4): 377-394.

Hirschman, E.C., Ruvio, A. and Belk, R.W. (2012) Exploring space and place in marketing research: Excavating the garage. Marketing Theory 12(4): 369-389.

Holt, D.B. and Thompson, C.J. (2004) Man-of-action heroes: The pursuit of heroic masculinity in everyday consumption. Journal of Consumer Research 31(2): 425-440.

Hulten, B. (2015) The impact of sound experiences on the shopping behaviour of children and their parents. Marketing Intelligence \& Planning 33(2): 197-215.

Kärrholm, M. (2005) Territorial complexity in public places - A study of territorial production at three squares in Lund. Nordisk arkitekturforskning (Nordic Journal of Architectural Research) 18(1): 99-114.

Kärrholm, M. (2007) The materiality of territorial production. Space \& Culture 10(4): 437453.

Karrholm, M. (2008) The territorialisation of a pedestrian precinct in Malmö: Materialities in the commercialisation of public space. Urban Studies 45(9): 1903-1924.

Kärrholm, M. (2009) To the rhythm of shopping - on synchronisation in urban landscapes of consumption. Social \& Cultural Geography 10(4):421-440.

Kärrholm, M. (2012) Retailising Space: Architecture, Retail and the Territorialising of Public Space. Farnham: Ashgate Publishing.

Kavaratzis, M. and Hatch, M.J. (2013) The dynamics of place brands an identity-based approach to place branding theory. Marketing Theory 13(1): 69-86.

Kusenbach, M. (2003) Street phenomenology the go-along as ethnographic research tool. Ethnography 4(3): 455-485.

Latour, B. (2005) Reassembling the Social: An Introduction to Actor-Network-Theory. Oxford: Oxford University Press.

Lefebvre, H. (2004) Rhythmanalysis: Space, Time and Everyday Life. Translated by Stuart Elden and Gerald Moore. London: Continuum.

Maas, J., Spreeuwenberg, P., van Winsum-Westra, M., Verheij, R.A., de Vries, S. and Groenewegen, P.P. (2009) Is green space in the living environment associated with people's feelings of social safety? Environment and Planning A 41(7): 1763-1777.

Maclaran, P. and Brown, S. (2005) The Center Cannot Hold: Consuming the Utopian Marketplace. Journal of Consumer Research 32(2): 311-323.

Mitchell, D. (1995) The end of public space? People's park, definitions of the public and 
democracy. Annals of the Association of American Geographers 85(1): 108-133.

Moisander, J., Valtonen, A. and Hirsto, H. (2009) Personal interviews in cultural consumer research - post-structuralist challenges. Consumption, Markets \& Culture 12(4): 329348.

ONS (2014) Census Analysis. London: Office for National Statistics.

Palmer, M., Medway, D., \& Warnaby, G. (2016). Theorizing temporary spatial clusters and institutional boundary-work in industrial marketing. Industrial Marketing Management. http://dx.doi.org/10.1016/j.indmarman.2016.06.010

Pink, S. (2013) Doing Visual Ethnography. $3^{\text {rd }}$ Edition, London: Sage Publications.

Pred, A. R. (1984) Place as historically contingent process: Structuration and the timegeography of becoming places. Annals of the Association of American Geographers 74(2): 279-297.

Sack, R.D. (1986) Human Territoriality: Its Theory and History. Cambridge: Cambridge University Press.

Schmitt, B. (1999) Experiential Marketing. Journal of Marketing Management 15(1): 53-67.

Sherry, J.F. Jr. (ed.) (1998) Servicescapes: The Concept of Place in Contemporary Markets, Chicago: NTC Business Books.

Spencer, S. (2011) Visual Research Methods in the Social Sciences. Oxon: Routledge.

Thomas, T.C., Price, L.L. and Schau, H.J. (2013) When differences unite: Resource dependence in heterogeneous consumption communities. Journal of Consumer Research 39(5): 1010-1033.

Thrift, N. (1997) The still point. Resistance, expressive embodiment and dance. In: Pile, S. and Keith, M. (eds.) Geographies of Resistance, pp.124-151. London: Routledge.

Thrift, N. (2008) Non-representational theory: Space, politics, affect. London: Routledge.

Tuan, Y.F. (1974) Topophilia: A Study of Environmental Perception, Attitudes, and Values. New York: Columbia University Press.

Tuan, Y.F. (1977) Space and Place: The Perspective of Experience. Minneapolis: University of Minnesota Press.

Visconti, L.M., Sherry, J.F., Borghini, S. and Anderson, L. (2010) Street art, sweet art? Reclaiming the "Public" in public space. Journal of Consumer Research 37: 511-529.

Warnaby, G. and Medway, D. (2013) What about the 'place' in place marketing? Marketing Theory 13(3): 345-363.

Willis, P. (2005) The Ethnographic Imagination. Cambridge: Polity Press.

Zukin, S. (2010) Naked City: The Death and Life of Authentic Urban Places. Oxford: Oxford University Press. 
Image 1 Tangible Elements of Boundary-Making

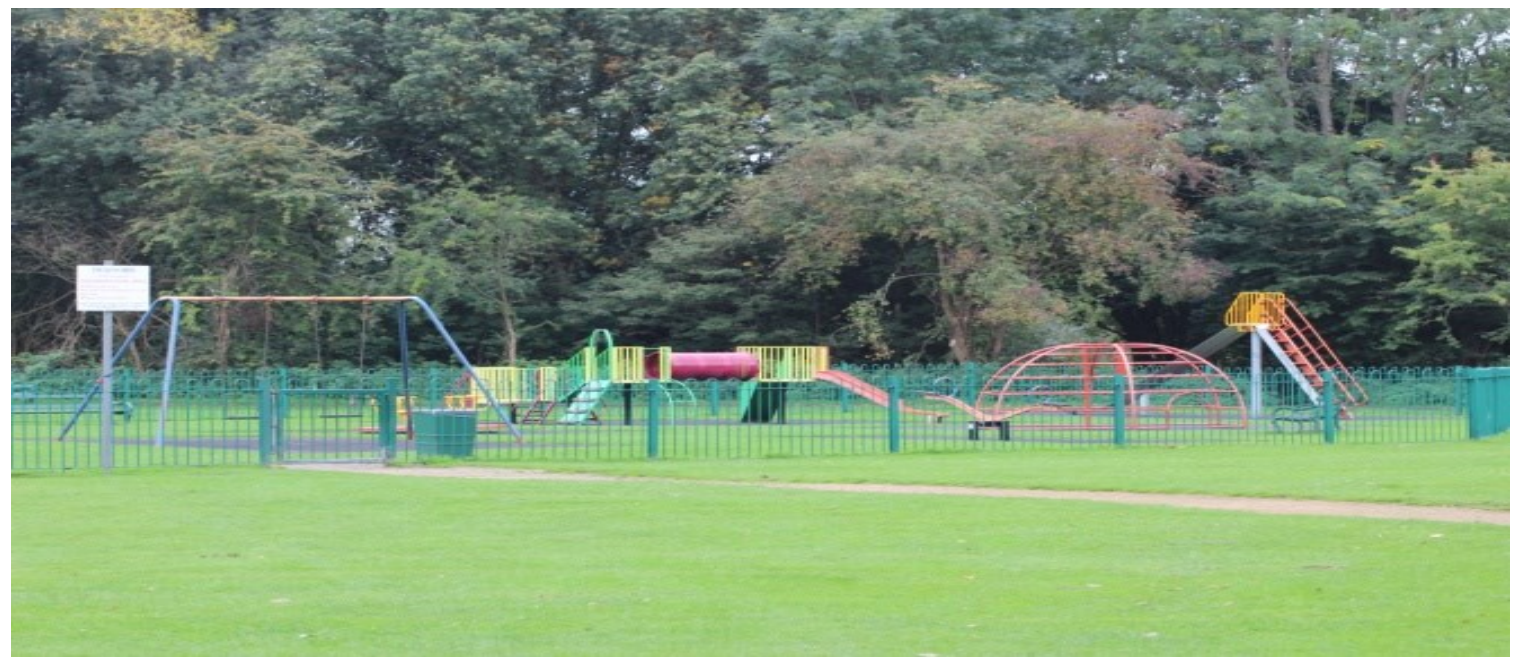

Image 2 Intangible Elements of Boundary-Making

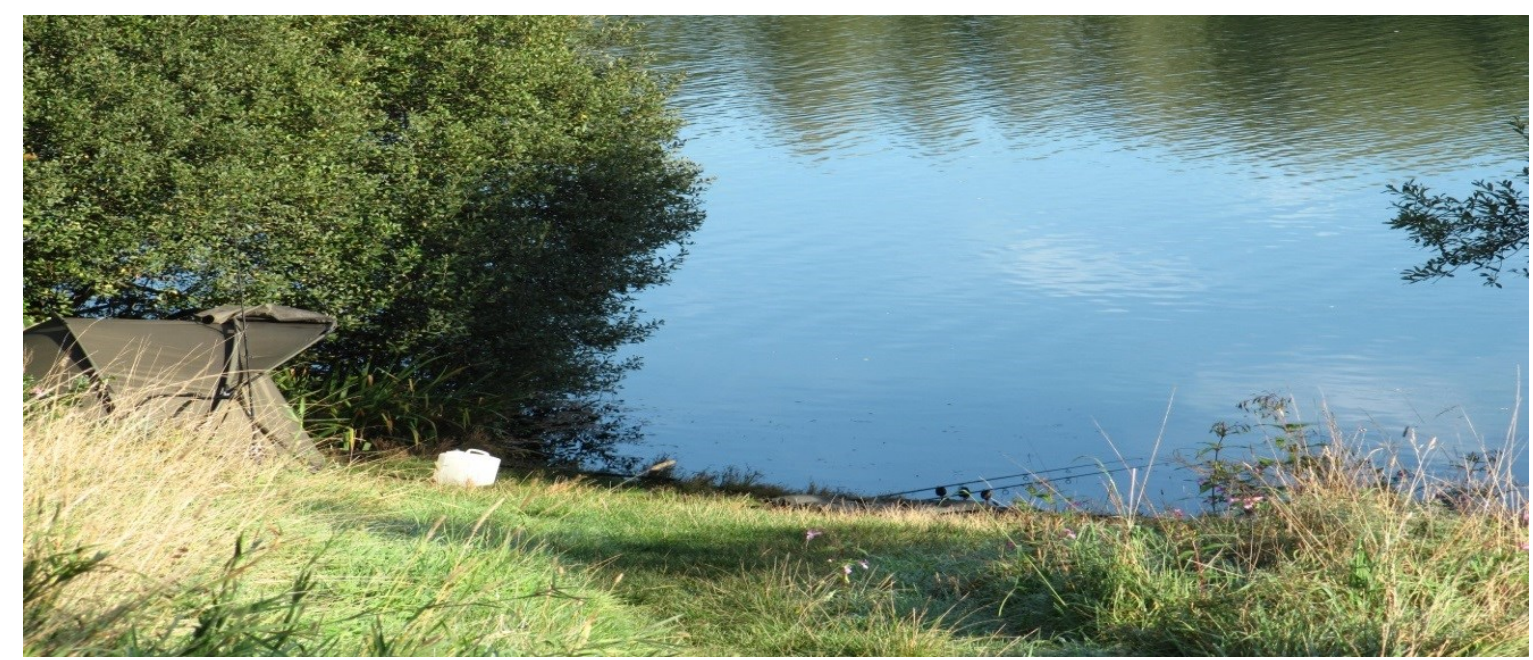

\section{Image 3 Synchronicity of Social Activities}

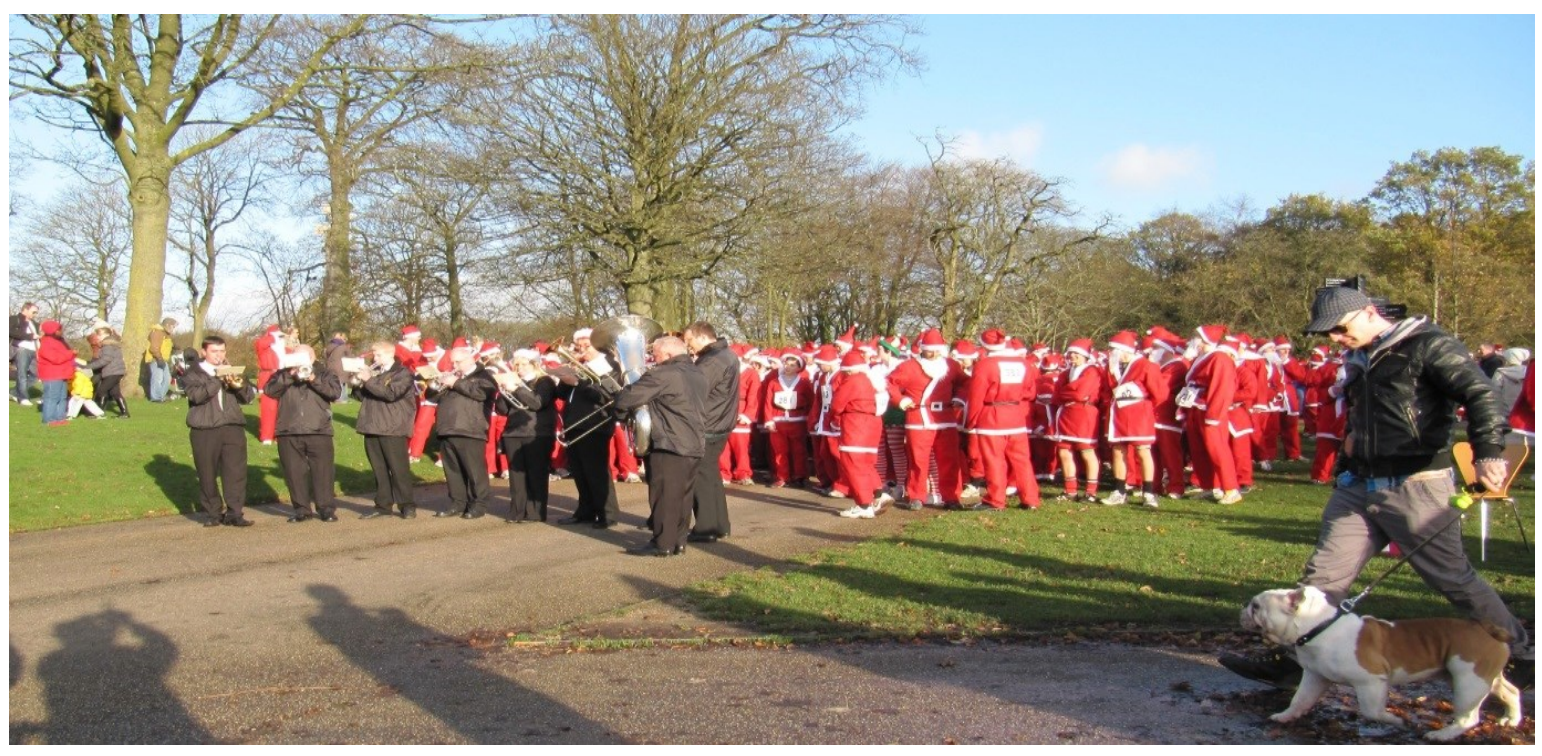


Image 4 Nature-Based Sensual Experiences

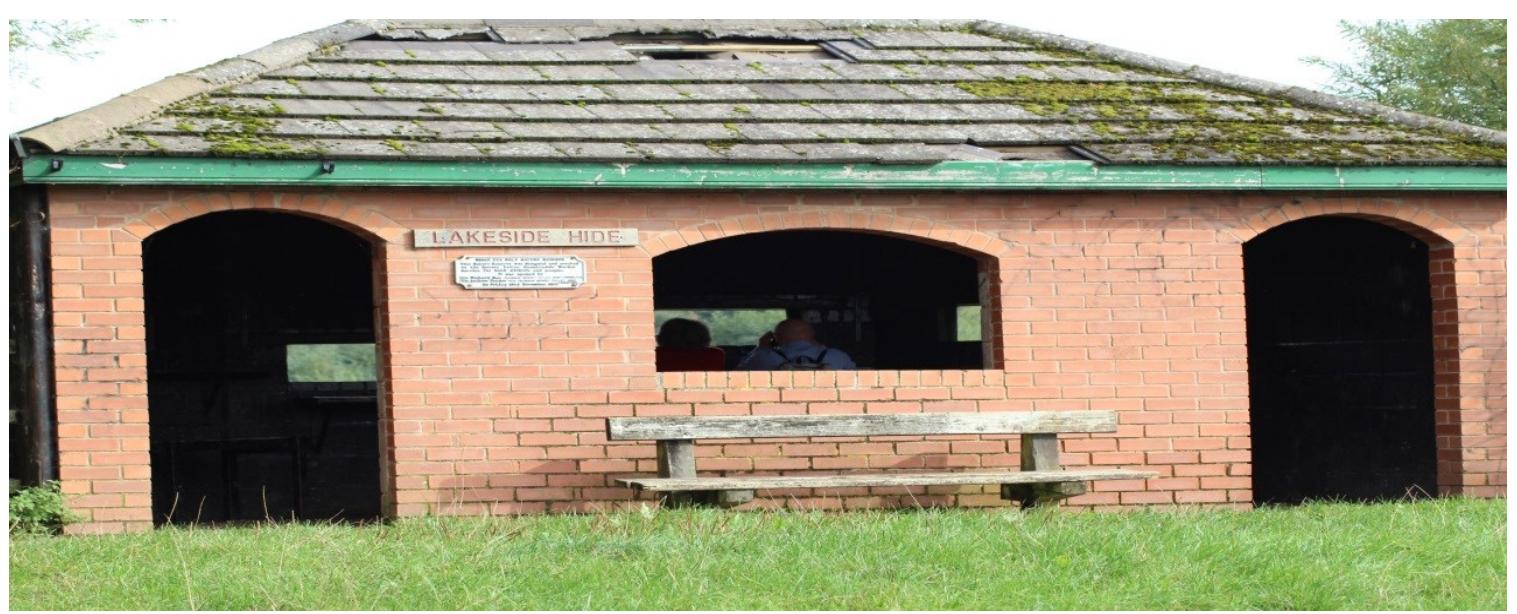

Image 5 Romanticisation of Sensual Experiences

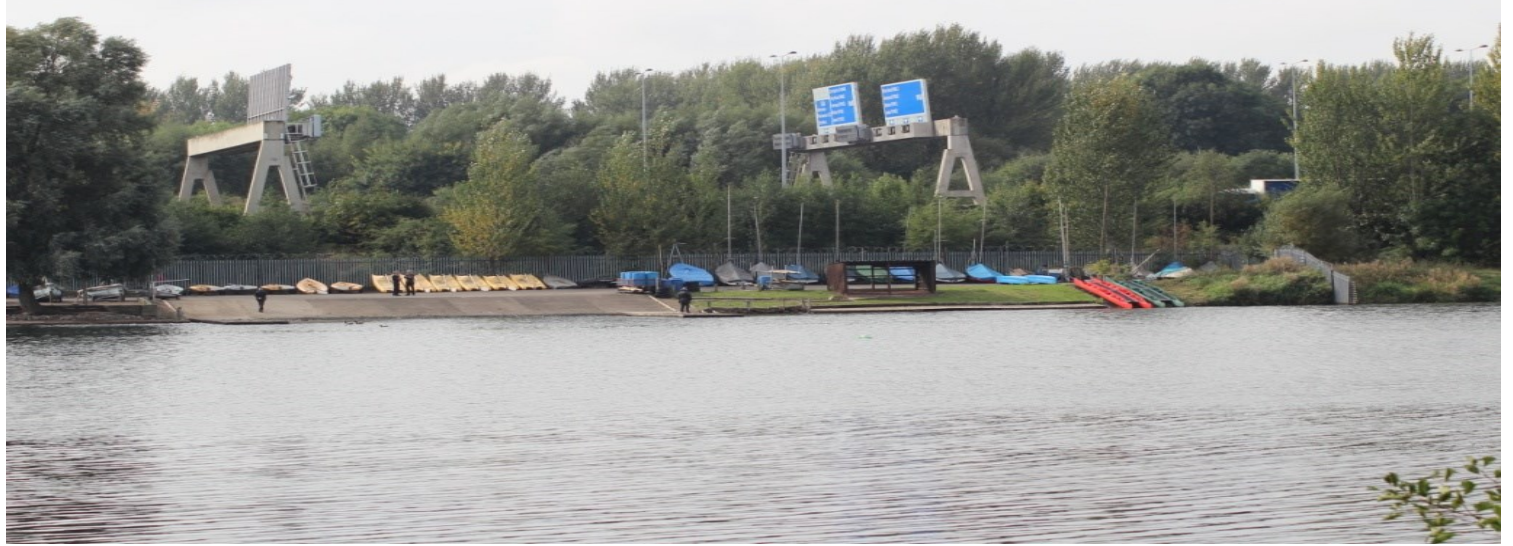

\section{Image 6 Socio-cultural Sensual Experiences}

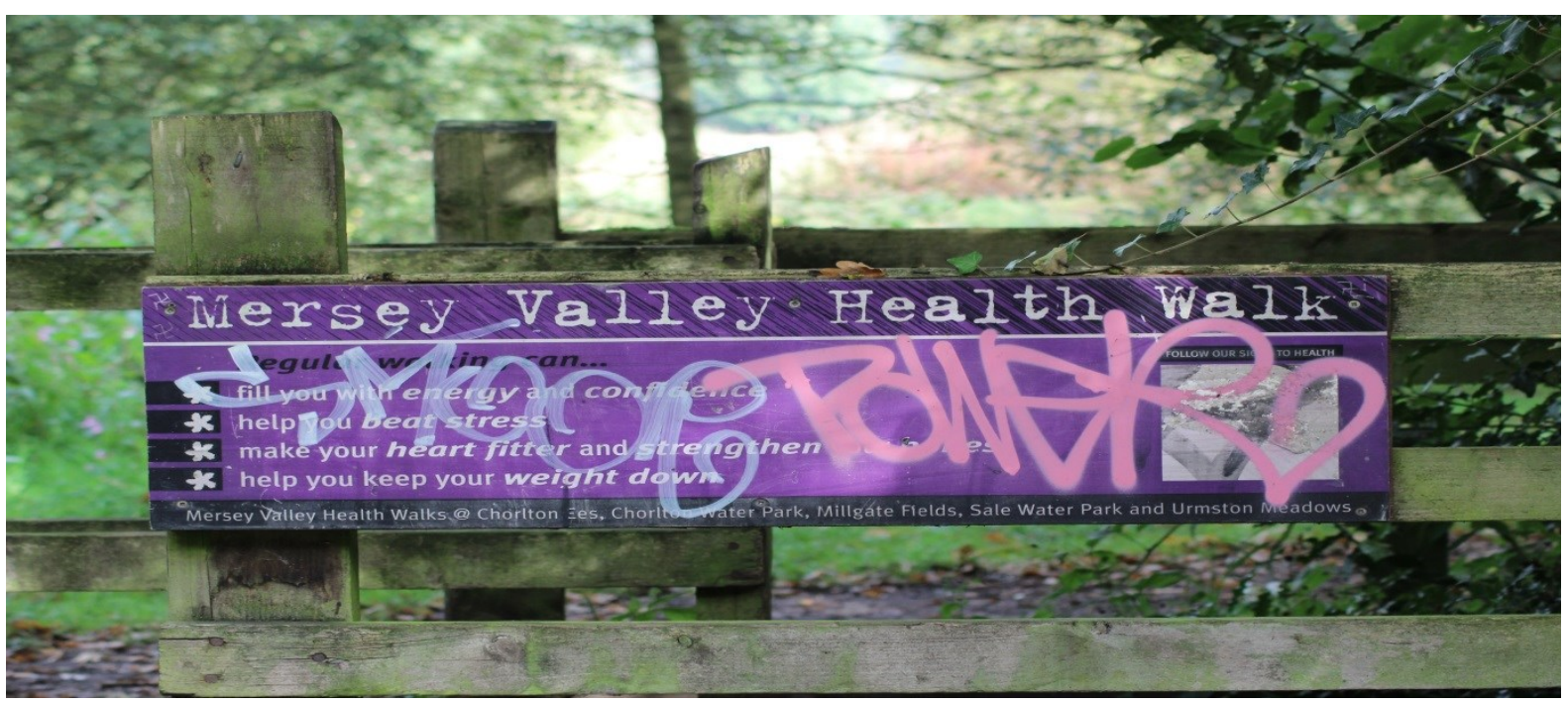

